\title{
Sulphasalazine-induced pseudomembranous colitis
}

\author{
Hugh J Freeman, MD, Urs P Steinbrecher, MD, WC Peter Kwan, MD, STEPHANIE ENSWorth, MD
}

HJ Freeman, UP Steinbrecher, WCP KWAN, S Ensworth. Sulphasalazine-induced pseudomembranous colitis. Can J Gastroenterol 1991;5(5): 167-170. An 18-year-old female with ankylosing spondylitis developed fever, abdominal pain and diarrhea on two occasions after starting sulphasalazine therapy. Flexible sigmoidoscopy revealed pseudomembranous colitis; fecal cultures were positive for Clostridium difficile; and C difficile toxin assay was positive. Despite the frequent use of sulphasalazine in the management of inflammatory bowel disease, this complication has been apparently rare. Clinicians should be wary of the onset of diarrhea in patients receiving sulphasalazine, whether for inflammatory bowel disease or other conditions.

Key Words: 5-aminosalicylic acid, Clostridium, Crohn's disease, Inflammatory bowel disease, Pseudomembranous colitis, Sulfapyridine, Sulphasalazine, Ulcerative colitis

\section{Colite pseudomembraneuse induite par la sulfasalazine}

RESUME: Une patiente âgée de 18 ans et atteinte d'une spondylarthrite ankylosante a souffert de fièvre, de douleurs abdominales et de diarrhée en deux occasions, après avoir entamé un traitement par la sulfasalazine. Une sigmoïdoscopie a révélé une colite pseudomembraneuse. Le diagnostic a été confirmé par une coproculture à la recherche de Clostridium difficile et la mise en évidence de sa toxine. Malgré le recours fréquent à la sulfasalazine dans le traitement des maladies inflammatoires de l'intestin, cette complication est apparemment rare. Les cliniciens devraient être attentifs à l'apparition de diarrhée chez les patients traités sous sulfasalazine, qu'ils soient porteurs d'une maladie inflammatoire de l'intestin ou d'une affection autre.

Department of Medicine (Gastroenterology and Rheumatology), University Hospital and University of British Columbia, Vancouver, British Columbia

Correspondence and reprints: Dr Hugh Freeman, ACU F-137, Gastroenterology, University Hospital (UBC site), 2211 Wesbrook Mall, Vancouver, British Columbia V6T IW5.

Telephone (604) $822-7216$

Received for publication May 9, 1991. Accepted August 26, 1991
$\mathrm{F}$ OLLOWING THE DISCOVERY THAT sulphonamides possessed antibacterial action, they were commonly used in the treatment of many inflammatory diseases. Svartz $(1,2)$ initially used sulfapyridine with salicylic acid for treatment of rheumatoid arthritis, which eventually led to the development of sulphasalazine, a 5-aminosalicylic acid and sulfapyridine linked by an azo bond (Pharmacia Inc, Sweden), for ulcerative colitis. Subsequent investigations suggested that 5 . aminosalicylic acid was the therapeutically active moiety (3-5). More recently, 'second generation' agents have been developed to circumvent side effects attributed to sulphasalazine, particularly the sulfapyridine component. Despite reported adverse effects, sulphasalazine remains useful in the management of patients with inflammatory bowel disease, and recent studies have suggested efficacy of this agent in some rheumatic disorders, eg, rheumatoid arthritis $(6,7)$.

A number of gastrointestinal complications of sulphasalazine have been recognized. Commonly described side effects are nausea, vomiting, anorexia and abdominal pain, while others in- 
clude pancreatitis, hepatitis, and skin and mucous membrane involvement (ie, Stevens-Johnson syndrome) (8). In recent years, sulphasalazine-induced exacerbations of colitis and diarrhea have been recorded in a number of patients (9-12). While most antibiotics have been implicated in the pathogenesis of pseudomembranous colitis, only limited information is available on the potential role of sulphonamides, such as sulphasalazine. This seems surprising given their widespread use, particularly in patients with inflammatory bowel disease.

The present report describes a patient with ankylosing spondylitis who developed abdominal pain, fever and diarrhea following sulphasalazine administration. Subsequent investigations failed to disclose a cause for her symptoms, but soon after re-introduction of sulphasalazine for a rheumatological disorder, diarrhea recurred, sigmoidoscopy showed the presence of pseudomembranous colitis, and stools were positive for Clostridium difficile cytotoxin.

\section{CASE PRESENTATION}

An 18-year-old female with a three year history of ankylosing spondylitis was referred for evaluation of abdominal pain and diarrhea for at least four weeks. Her spondylitis had failed to respond to standard nonsteroidal antiinflammatory medications, and required treatment with prednisone $10 \mathrm{mg}$ daily and phenylbutazone $100 \mathrm{mg}$ tid. A trial of therapy with sulphasalazine resulted in epigastric pain, fever and watery diarrhea three days following initiation of a $500 \mathrm{mg}$ daily dose. Because abdominal pain and diarrhea persisted after discontinuation of the sulphasalazine, the patient was admitted eight days later to her community hospital for investigation.

Physical examination revealed a temperature of $38^{\circ} \mathrm{C}$ and a diffusely tender abdomen. Hemoglobin was 100 $\mathrm{g} / \mathrm{L}$ with a white blood cell count of $12,800 / \mathrm{mm}^{3}$. Blood tests including serum amylase and liver chemistry tests (serum bilirubin, alkaline phosphatase and aminotransferases) were normal. Abdominal radiographs and ultrasound showed no abnormalities except for some free intrapelvic fluid. Gynecological examination and laparoscopy revealed a small amount of free fluid but no intra-abdominal or gynecological abnormality; the appendix, small intestine and colon appeared normal. Sigmoidoscopy, fecal cultures and an upper gastrointestinal tract barium study with small bowel follow-through were normal. Rectal biopsy and fecal toxin assay for $\mathrm{C}$ difficile were not done. All medications were discontinued except prednisone, which was increased to $40 \mathrm{mg}$ daily because of worsening back stiffness and pain. Over the next 20 days, the abdominal pain, fever and diarrhea resolved, and the prednisone was tapered to $10 \mathrm{mg}$ daily with re-institution of phenylbutazone $100 \mathrm{mg}$ tid. Because it was believed that the patient's abdominal pain was not explained, she was transferred to University Hospital for further evaluation. She had some mild epigastric discomfort. There was no previous personal or family history of gastrointestinal disease; the patient's brother had ankylosing spondylitis. Except for spondylitis, physical examination at the time of admission to University Hospital was normal.

Investigations revealed a hemoglobin of $96 \mathrm{~g} / \mathrm{L}$ with a white blood cell count of $16,700 / \mathrm{mm}^{3}$. Blood tests were normal, including liver chemistry (serum bilirubin, alkaline phosphatase and aminotransferases), serum amylase, electrolytes, carotene, calcium, phosphate, ferritin, vitamin $B_{12}$ and red cell folate. Urinalysis was normal. Rheumatoid latex test and antinuclear antibodies were negative. Blood, urine and fecal cultures (campylobacter, salmonella, shigella, aeromonas, yersinia and C difficile) were negative. Fecal parasite studies were negative, as were latex agglutination and tissue culture assays for C difficile cytotoxin. Fibreoptic endoscopic examination of the upper and lower gastrointestinal tract with biopsies of the stomach, duodenum and colon were normal. Repeat barium radiographs of the esophagus, stomach and small intestine were normal.

During the next week in hospital, the symptoms of the patient's spondylitis remained unchanged despite dis- continuation of prednisone. In an effort to reduce reliance on phenylbutazone, sulphasalazine $500 \mathrm{mg}$ daily was re-in. stituted; recurrent abdominal pain and diarrhea developed approximately $2 \mathrm{~h}$ after ingestion of the fourth $500 \mathrm{mg}$ tablet. Flexible sigmoidoscopy was repeated the following day and revealed multiple pseudomembranes from 5 to $25 \mathrm{~cm}$; biopsies confirmed pseudomem. branous colitis. Repeat fecal cultures were negative except for detection of $\mathrm{C}$ difficile; fecal $\mathrm{C}$ difficile cytotoxin tissue culture assay was now positive at a titre of greater than 1:1000. An indium. labelled white blood cell scan revealed increased diffuse activity within the large bowel. Oral vancomycin $500 \mathrm{mg}$ qid was instituted, but abdominal pain and diarrhea persisted, and fever over $39^{\circ} \mathrm{C}$ developed. Abdominal films revealed dilated small and large bowel but no free air in the peritoneal cavity. Intravenous metronidazole 500 mg every $12 \mathrm{~h}$ was added after two days, along with central venous total parenteral nutrition. Over the next two weeks, the patient's symptoms gradually resolved, permitting re-institution of oral intake and discontinuation of medications. Repeat flexible sigmoidoscopy with biopsy was normal, and fecal $\mathrm{C}$ difficile cytotoxin assays were negative.

\section{DISCUSSION}

The present patient was referred because of fever, abdominal pain and watery diarrhea following administration of enteric-coated sulphasalazine (Salazopyrin; Pharmacia Inc, Sweden). Initial investigations prior to re-introduction of sulphasalazine, including fecal cultures, toxin assays, endoscopy and contrast radiographs of the gastrointestinal tract, were normal. The patient's symptoms resolved spontaneously, but recurred promptly after challenge with sulphasalazine. Sub. sequent studies revealed histologically confirmed pseudomembranous colitis associated with $\mathrm{C}$ difficile cytotoxin. While this agent has been widely used in the past for the treatment of inflam. matory bowel disease, the patient described in the current report was treated with sulphasalazine in an effort 
to control symptoms associated with ankylosing spondylitis. Although there is one prior report of pseudomembranous colitis attributed directly to sulphasalazine treatment, this occurred in a patient with pre-existing Crohn's disease (13). The present patient had no history suggesting a preexisting primary gastrointestinal disorder, and investigations of the gastrointestinal tract performed only a short time prior to re-introduction of sulphasalazine for spondylitis were normal. The observations in the present patient provide strong evidence that $\mathrm{C}$ difficile-associated diarrhea and pseudomembranous colitis may develop in patients treated with sulphasalazine. To date, this complication has not been reported with other 5-aminosalicylic acid-containing products.

Prior reports have documented a number of adverse gastrointestinal specifically colonic - effects after sulphasalazine administration. Werlin and Grand (9) described two children with ulcerative colitis and bloody diarrhea following sulphasalazine administration; symptoms also recurred with

\section{REFERENCES}

1. Svartz N. Salazopyrin, a new sulfonilamide preparation. Acta Med Scand 1942;110:557-98.

2. Svartz N. The treatment of 124 cases of ulcerative colitis with Salazopyrin and attempts at desensitization in cases of hypersensitiveness to sulfa. Acta Med Scand 1948;206:465-72.

3. Azad Khan AK, Piris J, Truelove SC. An experiment to determine the active therapeutic moiety of sulphasalazine. Lancet 1977;ii:892-5.

4. van Hees PAM, Bakker JH, van Tongeren JHM. Effect of sulphapyridine, 5-aminosalicylic acid, and placebo in patients with idiopathic proctitis: A study to determine the active therapeutic moiety of sulphasalazine. Gut 1980;21:632-5.

5. Campieri M, Lanfranchi G, Bazzocchi $\mathrm{G}$, et al. Treatment of ulcerative colitis with high dosage 5-aminosalicylic acid enemas. Lancet 1981; ii:270-1.

6. Dixon JS. Biochemical and clinical changes in rheumatoid arthritis: Their relation to the action of antirheumatoid drugs. Semin Arthrit is Rheum 1982;12:191-207. drug challenge and rapidly resolved with cessation of sulphasalazine. Schwartz et al (10) described challenge studies in a 35-year-old physician following oral and rectal sulphasalazine administration. Endoscopic and histological relapse of ulcerative colitis, as well as iridocyclitis, followed both routes of drug delivery. Similar observations were made in a nine-year-old male with pre-existing ulcerative colitis; in this patient, however, an assay for $\mathrm{C}$ difficile cytotoxin was negative (12). Pseudomembranous colitis and a positive assay for $\mathrm{C}$ difficile cytotoxin were described in a patient with known Crohn's disease (13); sigmoidoscopic examination three months earlier showed only "diffuse mucosal edema and multiple ulcerations" without pseudomembranes. Fecal studies were not reported prior to sulphasalazine administration. Subsequent sulphasalazine therapy, however, resulted in symptomatic relapse; repeat endoscopic evaluation showed pseudomembranous colitis and concomitant detection of C difficile cytotoxin. Although $\mathrm{C}$ difficile cytotoxin has been frequently isolated from patients with well established inflammatory bowel disease by different investigators (14-24), its role in disease pathogenesis remains unclear. It is, however, intriguing that pseudomembranes have rarely been recorded in this setting $(14,15)$, perhaps reflecting limited pathological reactivity of the colonic mucosa in patients with either ulcerative colitis or Crohn's disease in response to toxin(s) from this organism.

The present report describes endoscopic, histological and microbiological studies showing $\mathrm{C}$ difficile-related pseudomembranous colitis in a patient administered sulphasalazine for ankylosing spondylitis; unequivocally normal studies were documented immediately prior to drug administration. Although surprisingly rare in view of its common use, sulphasalazine evidently has the potential to cause a lifethreatening disorder, pseudomembranous colitis. As such, clinicians should be very wary of the onset of diarrhea in patients administered sulphasalazine, including patients treated for disorders other than inflammatory bowel disease.

toxin during relapse of chronic inflammatory bowel disease. Lancet 1980;i:381-4.

15. Trnka YM, LaMont JT. Association of Clostridium difficile toxin with symptomatic relapse of chronic inflammatory bowel disease. Gastroenterology 1981;80:693-6.

16. Meyers S, Mayer L, Bottone E, Desmond E, Janowitz HD. Occurrence of Clostridium difficile toxin during the course of inflammatory bowel disease. Gastroenterology 1981;80:697-700.

17. Dorman SA, Liggoria E, Winn WC, Beeken WL. Isolation of Clostridium difficile from patients with inactive Crohn's disease. Gastroenterology 1982;82:1348-51.

18. Bolton RP, Read AE. Clostridium difficile in toxic megacolon complicating acute inflammatory bowel disease. $\mathrm{Br}$ Med J 1982;285:475-6.

19. Keighley MRB, Youngs D, Johnson M, Allan RN, Burdon DW. Clostridium difficile toxin in acute diarrhea complicating inflammatory bowel disease. Gut 1982;23:410-4.

20. Greenfield C, Aguilar Ramirez JR, 
Pounder RE, et al. Clostridium difficile and inflammatory bowel disease. Gut 1983;24:713-7.

21. Rolny P, Jarnerot G, Mollby R. Occurrence of Clostridium difficile toxin in inflammatory bowel disease. Scand J Gastroenterol 1983;18:61-4.
22. Wright JM, Adams SP, Gribble MJ, Bowie WR. Clostridium difficile in Crohn's disease. Can J Surg 1984;27:435-7.

23. Hyams JS, McLaughlin JC. Lack of relationship between Clostridium difficile toxin and inflammatory bowel disease in children. J Clin Gastroenterol 1985;7:387-90.

24. DeRidder PH, Kadro O.

Crohn's disease with persistence of Clostridium difficile, surgical elimination. J Clin Gastroenterol 1985;7:269-72. 


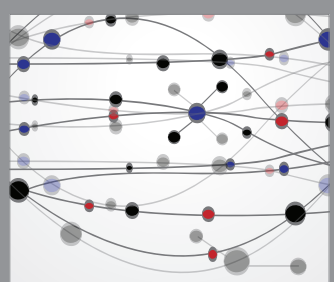

The Scientific World Journal
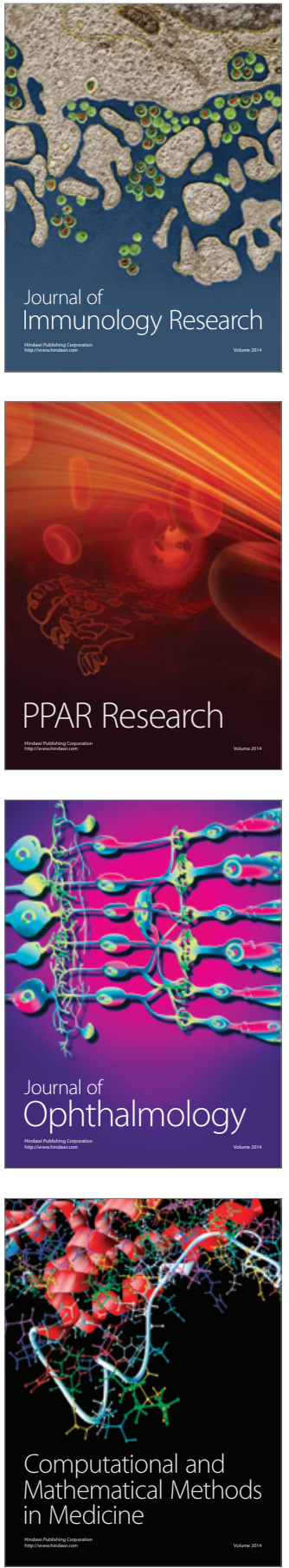

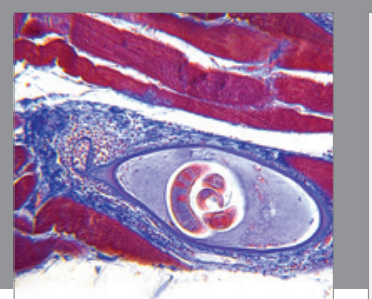

Gastroenterology Research and Practice

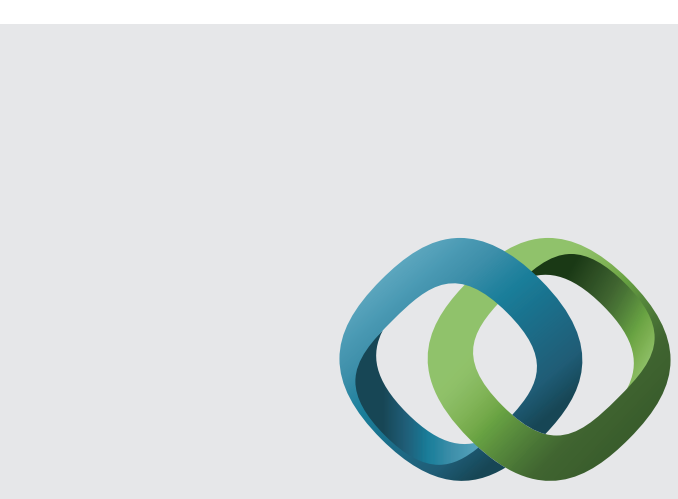

\section{Hindawi}

Submit your manuscripts at

http://www.hindawi.com
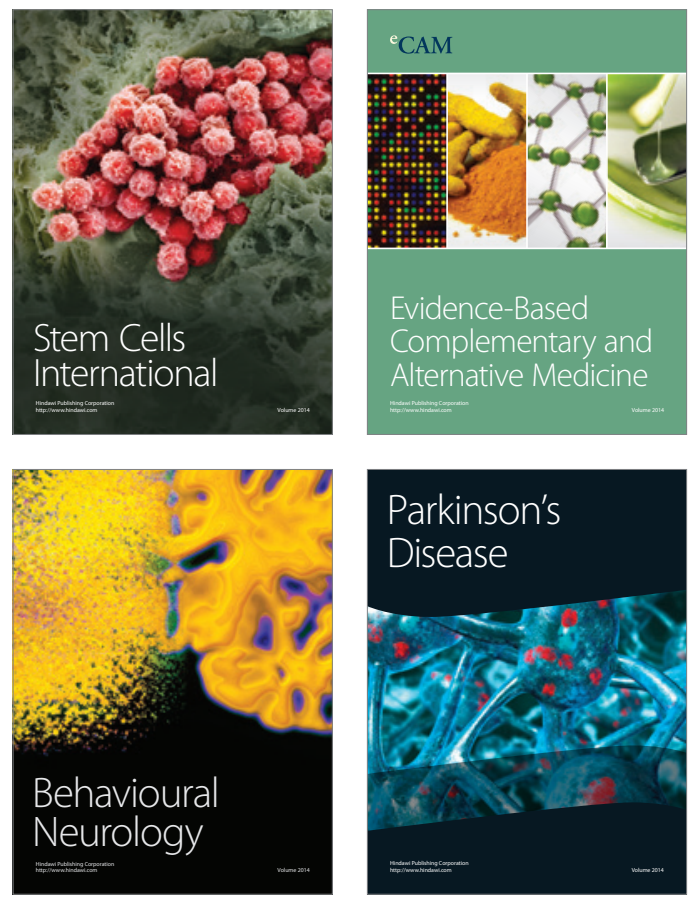
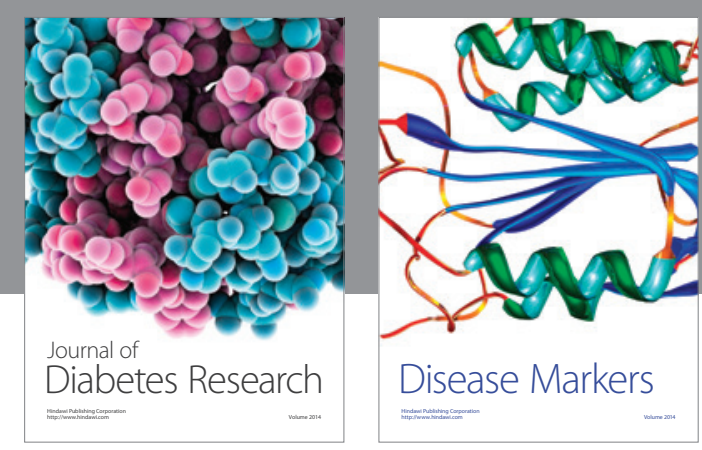

Disease Markers
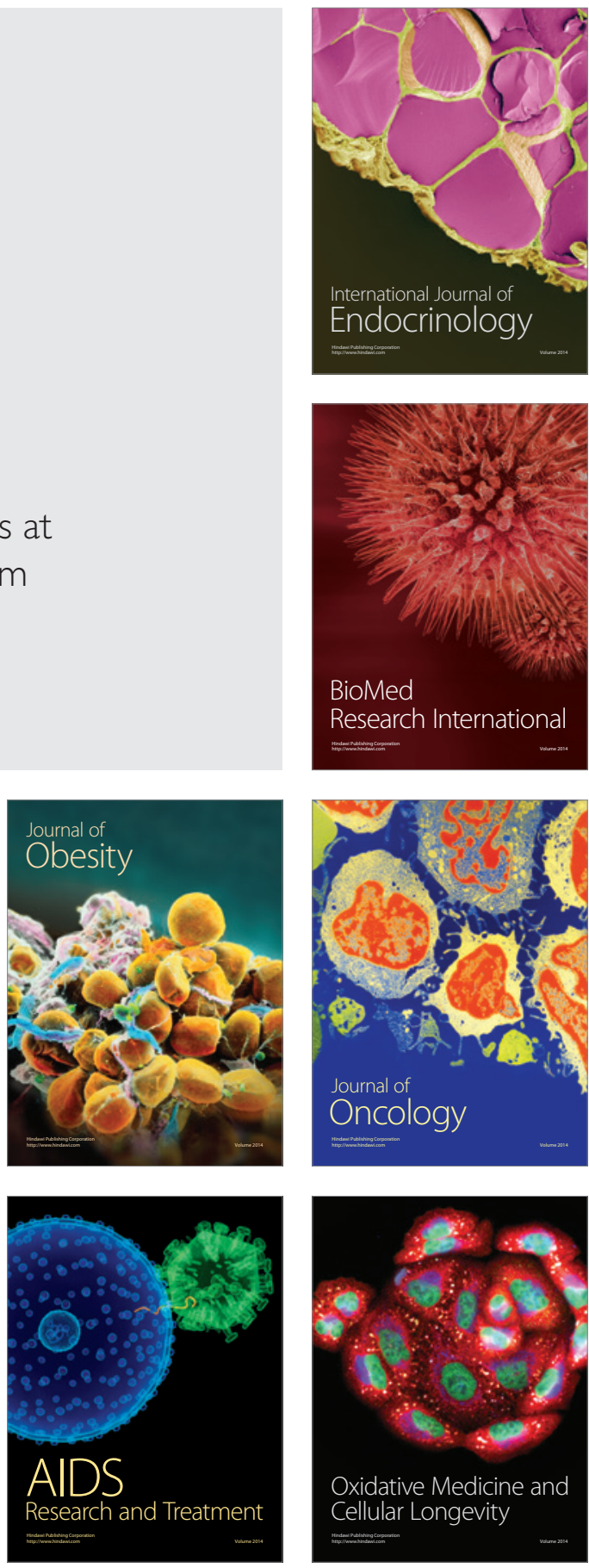